\title{
Proposal for an approach to evaluate continuity in service supply chains: case of the Moroccan electricity supply chain
}

\author{
Houda Mezouar, Abdellatif El Afia
}

National Superior School of Computer Science and Systems Analysis, Mohammed V University of Rabat, Morocco

\begin{tabular}{l}
\hline \hline Article Info \\
\hline Article history: \\
Received Jul 18, 2018 \\
Revised Jun 28, 2019 \\
Accepted Jul 17, 2019 \\
\hline Keywords: \\
BPM \\
Electricity supply chain \\
KPIs \\
Root cause analysis tree diagram \\
SCOR \\
Service supply chain \\
Smart supply chain \\
\end{tabular}

\begin{abstract}
The purpose of this paper is to develop an approach to analyse and evaluate continuity in Service Supply Chain (SSC), through a case study. This approach is based on the data-driven quality strategy "Define, Measure, Analyze, Improve, Control" (DMAIC) which is used to drive Six Sigma projects, and on the characteristics of Smart Supply Chain. It combines Business process management (BPM), Supply Chain Operations Reference (SCOR), and the Root cause analysis tree diagram. The chosen case study is the electricity SCC, especially the business process 'management of electricity for residential buildings' of the Moroccan electricity SSC. The paper shows that the suggested approach identifies the discontinuity causes for the studied SSC, improves the business process behavior and manages its control by providing a dashboard that encompasses KPIs for periodically controlling of the SSC "to-be" state.
\end{abstract}

Copyright $@ 2019$ Institute of Advanced Engineering and Science. All rights reserved.

\section{Corresponding Author:}

Houda Mezouar,

National Superior School of Computer Science and Systems Analysis,

Mohammed V University of Rabat,

168 ENSIAS, Mohamed Ben Abdellah Regragui Avenue, Rabat, Morocco.

Email: houda.mezouar@gmail.com

\section{INTRODUCTION}

Nowadays, the world economy has grown progressively service oriented and an increasing attention on SSC by both practitioners and academics is noticed. Actualy, in a supply chain, there is a product created by the points of origin and delivered at the points of consumption. When the product is not a physical product, we talk about a SSC [1,2]. Despite this difference of product nature, in the manufactoring supply chain as in SSC, the objective of achieving efficiency and responsiveness is equally important and relevant. Moreover, maintaining SSC operations, can be a major challenge for organizations. Part of what makes continuity such a challenge for SSC in a general way, and particullary for the electrical SSC which is caracterised by the stochastic nature of electricity production and the time varying load demand. And since the majority of the performance works in electricity field are interested in only one process (example: electricity generation) without taking into account the impact on the whole SSC, or they are interested to a performance at the operational level by studying a single device (example: smart meter) without considering the whole process [3-8], it makes this service (electricity) a good case study for a global SSC analysis approach.

Apart from its capacity to guide actions, a holistic view of SSC has an explanation and description capacity, in this context, [9-13] proposed modelling methodologies for SSC analysis wich combines different methods and tools, aiming to provide a capture of the "as-is" state of the SSC, as credible as possible. In addition to describe the current SSC, this work propose an approach able to determine the causes of the service discontinuity, to correct the discontinuity and to control periodicaly the updated SSC. This approach is based on the data-driven quality strategy DMAIC of Six Sigma projects, and on 
the characteristics of Smart Supply Chain. It combines BPMN, BPM simulation, SCOR, and the Root cause analysis tree diagram. And it's proven by the case study of the Moroccan electricity SSC. The application of the proposed approach to the Moroccan electricity SSC, allowed us to analyze this SSC, to identify the discontinuity causes for the chosen business process, to propose a process improvement for the SSC, and to develop a dashboard for periodic control of the continuity management of this SSC. The reminder of this paper is organized as follows. Section 2 explains the proposed approach, used in this work to evaluate the performance of the studied SSC. The obtained results and analysis are explained in Section 3. Finally, Section 4 is a conclusion that synthesizes the achieved work.

\section{PROPOSED APPROACH}

The research was developed based on the case study of the business process 'the management of electricity for residential buildings' of the Moroccan electricity SSC.The performance methodology used is based on Six Sigma, this methodology brings structure to process improvement by providing the user with a more detailed outline of Deming's PDCA cycle by guiding the initiative through a five stage cycle known as DMAIC [14], which actually stands for the phases of the improvement projects Define, Measure, Analyze, Improve and Control [15]. The Table 1 explains the detail of the DMAIC adaptation to this paper purpose.

Table 1. DMAIC phases

\begin{tabular}{|c|c|}
\hline Phase & Detail \\
\hline Define & $\begin{array}{l}\text { This phase is done in [16] according to a methodology in fourth levels organized in a descending order (that is, from } \\
\text { the overall system, to decompose the latter into finer granularity subsystems), the three first levels are done with } \\
\text { SCOR and the last one is done with the BPMN. In this work we focus on the fourth level, and especially the business } \\
\text { process 'the management of electricity for residential buildings'. }\end{array}$ \\
\hline Measure & The second phase represents the results of the aforementioned model simulation using Bonita BPM. \\
\hline Analyze & In this phase the results of the simulation are analyzed and presented in a root cause analysis tree diagram. \\
\hline Improve & $\begin{array}{l}\text { In the fourth phase we take advantage of the principles of Smart Supply Chain presented in [17] to improve } \\
\text { the process of the first phase. }\end{array}$ \\
\hline
\end{tabular}

The following research questions are formulated as a basis for respecting our methodology:

RQ1: what is "the management of electricity for residential buildings" process of the current Morrocan supply chain of electricity?

RQ2: how can the characteristics of the Smart Supply Chain emphasize the intelligence of the studied business process?

RQ3: how can the reliability and reactivity of the proposed supply chain be evaluated?

\section{RESULTS AND ANALYSIS}

This section presents the five phase's results, done accordingly to the aforementioned approach, while responding to the research questions elaborated in the previous section. The first question is addressed by the first three phases, the second question by the fourth phase, and the last question by the last phase.

RQ1: what is "the management of electricity for residential buildings" process of the current Morrocan supply chain of electricity?

\subsection{Define phase}

The first phase consists of analyzing the studied business process and make it clear while offering a global view of the studied SSC. The business process 'the management of electricity for residential buildings' of the Moroccan supply chain of electricity is shown in Figure 1. The aim of this business process is to satisfy the end users' needs of electricity. At least one of the three start events shown in Figure 1 triggers the production of electricity: "producers' activity management", "sends the consumer profile" and "production plan". Electricity producers presented by the lane "private producer" are organizations whom the activity management generates electricity. These consume a generated electricity share and they sell a share of it to ONEE. For areas whose distribution is managed by private distributors (e.g. Redal), these distributors periodically sends to the ONEE the area consumption profile, if not for areas whose distribution is managed by the ONEE, it respects its production plan. Thus, to produce electricity, ONEE refers to data provided by the distributors or to its data (and not to both data sources, for the same area). The electricity supply is based on the production made by ONEE, import of electricity, or purchase of electricity (activities of the ONEE lane), once the electricity is generated, ONEE ensures its transport, and then depending on

\footnotetext{
Proposal for an approach to evaluate continuity in service supply chains: case of the ... (Houda Mezouar)
} 
the area it manages the distribution, or it sells it to distributors. The distributors buy electricity from ONEE and distribute it. The end user consumes electricity. These processes are managed by contracts between producers and ONEE, ONEE and distributors and between the user and the distributor. These contracts include various clauses specific to different situations. Other support processes are not shown in the figure, such as the management of transmission and distribution networks and the billing.

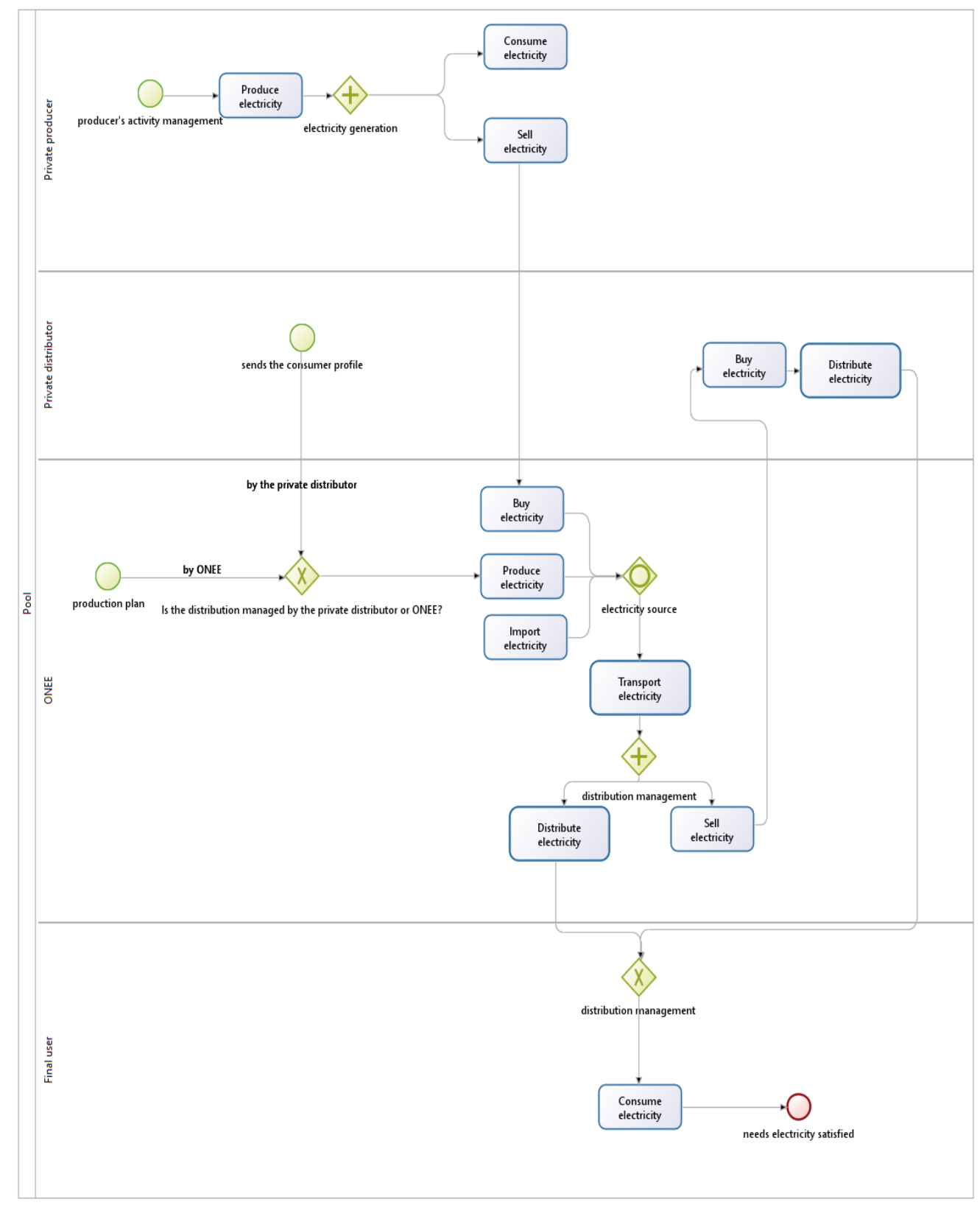

Figure 1. The business process 'management of electricity for residential buildings'

\subsection{Measure phase}

The second phase clarify the way the business process currently perform, for this phase the business process simulation is done using the same tool chosen for the modelling, with applying probabilities for the flow paths. Simulation can be applied for different purposes, namely prediction, performance, entertainment, training, education, confirmation and discovery. When a simulation is run, a specified number of iterations over a specified period of time are run either with simulated data or with assigned probabilities. In order to specify the scenarios to simulate, the form shown in Figure 2 is created, to feed our objects before launching the simulation. 


\section{G Bonitasoft}

Management of electricity for residential buildings parameters

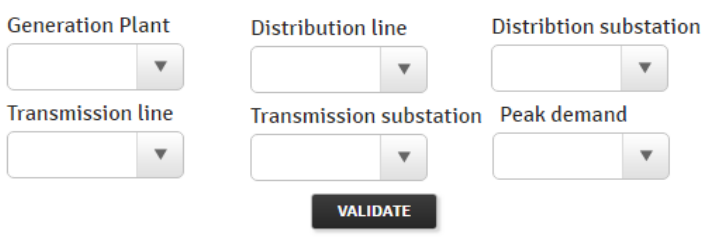

Figure 2. The business process form

This phase of our study considers six possible scenarios related to the resources specific to each task and to the various cases of this business process management. Table 2 shows the scenarios to simulate, in order to deduce the elements that impact the service continuity.

Table 2. The simulation scenarios

\begin{tabular}{|c|c|c|c|c|c|c|}
\hline & $\begin{array}{c}\text { Generation } \\
\text { plant failure }\end{array}$ & $\begin{array}{c}\text { Distribution line } \\
\text { failure }\end{array}$ & $\begin{array}{c}\text { Distribution } \\
\text { substation failure }\end{array}$ & $\begin{array}{c}\text { Transmission } \\
\text { line failure }\end{array}$ & $\begin{array}{c}\text { Transmission } \\
\text { substation failure }\end{array}$ & $\begin{array}{c}\text { Peak } \\
\text { demand }\end{array}$ \\
\hline Scenario 2 & False & True & False & False & False & False \\
\hline Scenario 4 & False & False & False & True & False & False \\
\hline Scenario 5 & False & False & False & False & True & False \\
\hline Scenario 6 & False & False & False & False & False & True \\
\hline
\end{tabular}

The Table 3 presents the minimum, the average and the maximum execution time (by hours) of the main tasks of the lanes ONEE and Final user, and which are: produce electricity, transport electricity, distribute electricity, and consume electricity. (Sc: Scenario, Mi: minimum, A: average, Ma: maximum). The load profile used in this work is composed of the start date 01-07-2018 at 00:00 am, the end date 31-07-2018 at 00:01 and 100 instances. The simulation is runed six times, and in each time, we have entered the parameters specific to each scenario.

Table 3. The execution time by activity

\begin{tabular}{|c|c|c|c|c|c|c|c|c|c|c|c|c|}
\hline \multirow[t]{2}{*}{ Scenario } & \multicolumn{3}{|c|}{ Produce electricity } & \multicolumn{3}{|c|}{ Transport electricity } & \multicolumn{3}{|c|}{ Distribute electricity } & \multicolumn{3}{|c|}{ consume electricity } \\
\hline & $\mathrm{Mi}$ & A & Ma & $\mathrm{Mi}$ & A & $\mathrm{Ma}$ & $\mathrm{Mi}$ & A & $\mathrm{Ma}$ & $\mathrm{Mi}$ & A & $\mathrm{Ma}$ \\
\hline Sc 2 & 103.667 & 250 & 697.21 & 0 & 293 & 561.08 & 0 & 0 & 0 & 0 & 0 & 0 \\
\hline Sc 4 & 103.43 & 249 & 697.09 & 232.78 & 339 & 722.083 & 0 & 439 & 530 & 0 & 0 & 0 \\
\hline Sc 5 & 111.09 & 250 & 690.821 & 199 & 267 & 673.98 & 0 & 102 & 295.12 & 0 & 0 & 0 \\
\hline Sc 6 & 109 & 259 & 729.68 & 299 & 378 & 651.88 & 287.08 & 390 & 721.51 & 369.245 & 411 & 712 \\
\hline
\end{tabular}

The discontinuity of the service is marked by the non-execution of the final event, and therefore according to our business process by the non-execution of the task "consume electricity", which corresponds to the scenarios $\operatorname{sc} 1 \operatorname{sc} 2 \operatorname{sc} 3 \operatorname{sc} 4$ and $\operatorname{sc} 5$.

\subsection{Analyze phase}

This phase allows to closely examine the process based on the results of the Measure phase. So, according to the BPMN model simulation, we conclude that "Generation plant failure", "Distribution line failure", "Distribtion substation failure", "Transmission line failure", "Transmission substation failure" are events that prevent the execution of the activity "consume electricity", which prevents the execution of the final event of our BPMN model and consuquensly causes a discontinuity int the SSC. Figure 3 shows the causes of the discontinuity for this business process. 


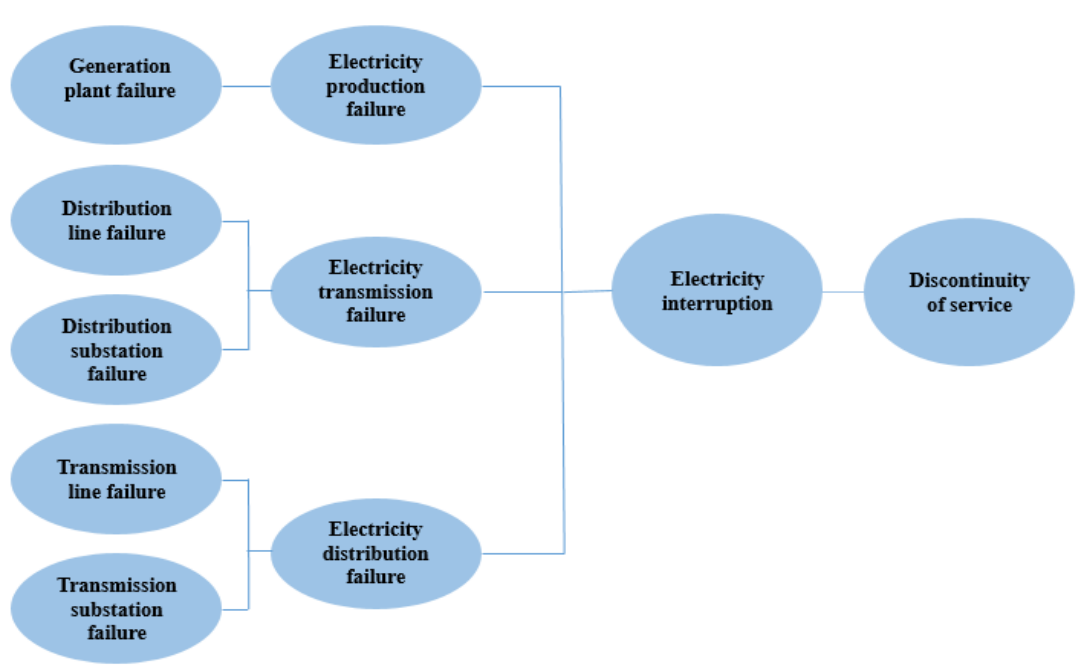

Figure 3. Root cause analysis tree diagram

Responding to RQ1, and making clear the way the business process perform, the resources and elements that could cause the discontinuity of the service, leads us to answer the second research question (RQ2).

RQ2: how can the characteristics of the Smart Supply Chain emphasize the intelligence of the studied business process?

\subsection{Improve phase}

As the world begins to work differently, we see a different kind of supply chain emerging a smarter supply chain with three core characteristics: Interconnected, Instrumented, Intelligent.

- 'Interconnected': Smarter supply chains will take advantage of a new levels of interaction with all objects of the supply chain. In addition to creating a global view of the supply chain, this interconnectivity will facilitate collaboration on a large scale [18].

- 'Instrumented': Sensors, Radio frequency identification (RFID) tags, meters, actuators, GPS and other devices and systems, will increasingly generate supply chain information that was previously created by people. The smarter supply chain will witness events as they occur [19].

- 'Intelligent': A smarter supply chain is able of learning and making decisions by itself, without human involvement. This intelligence will be used not only to make real-time decisions, but also to predict the future. Equipped with sophisticated modelling and simulation capabilities, the smarter supply chain will move past sense and-respond to predict-and-act [18].

The characteristic of the Smart Supply Chain that interests us in this work is "Interconnected". To meet the challenges of the current Supply Chain, we aim to make it more interconnected by integrating the end user as an actor in this chain. The end users are either major customers (factories, business ...) or individuals, and the predictions are based mainly on historical consumption which is almost unchanged for major customers, the forecast error is typically caused by individuals whose consumption is unpredictable. By integrating these individuals into this system we move from a traditional supply chain to an interconnected supply chain, where the final consumer participates by generating power at the point of consumption. In this case, individuals will consume electricity they produce, still linked to the national grid, they can (if needed) consume electricity provided by the network.

The proposed business process model is presented in Figure 2. This model is similar to the previous one, with the same start events, end event, and the three first lanes' activities namely: Private producer, Private distributor, and ONEE. The reconfiguration is made as an adding of two activities at the lane "Final user", and of a flow between "ONEE" and "Final user". These added activities reflect the fact that the end user (individual) can generate the electricity he needs. From a managerial side the implementation of this business rule is based on the management of some constraints such as electricity production prices by the individual must be less than or equal to that of its purchase of ONEE. This means that the management of the decentralized electricity production will add other support activities to the lane "ONEE" not shown in Figure 2 as encouraging individuals to follow this new policy as shown in Figure 4. 


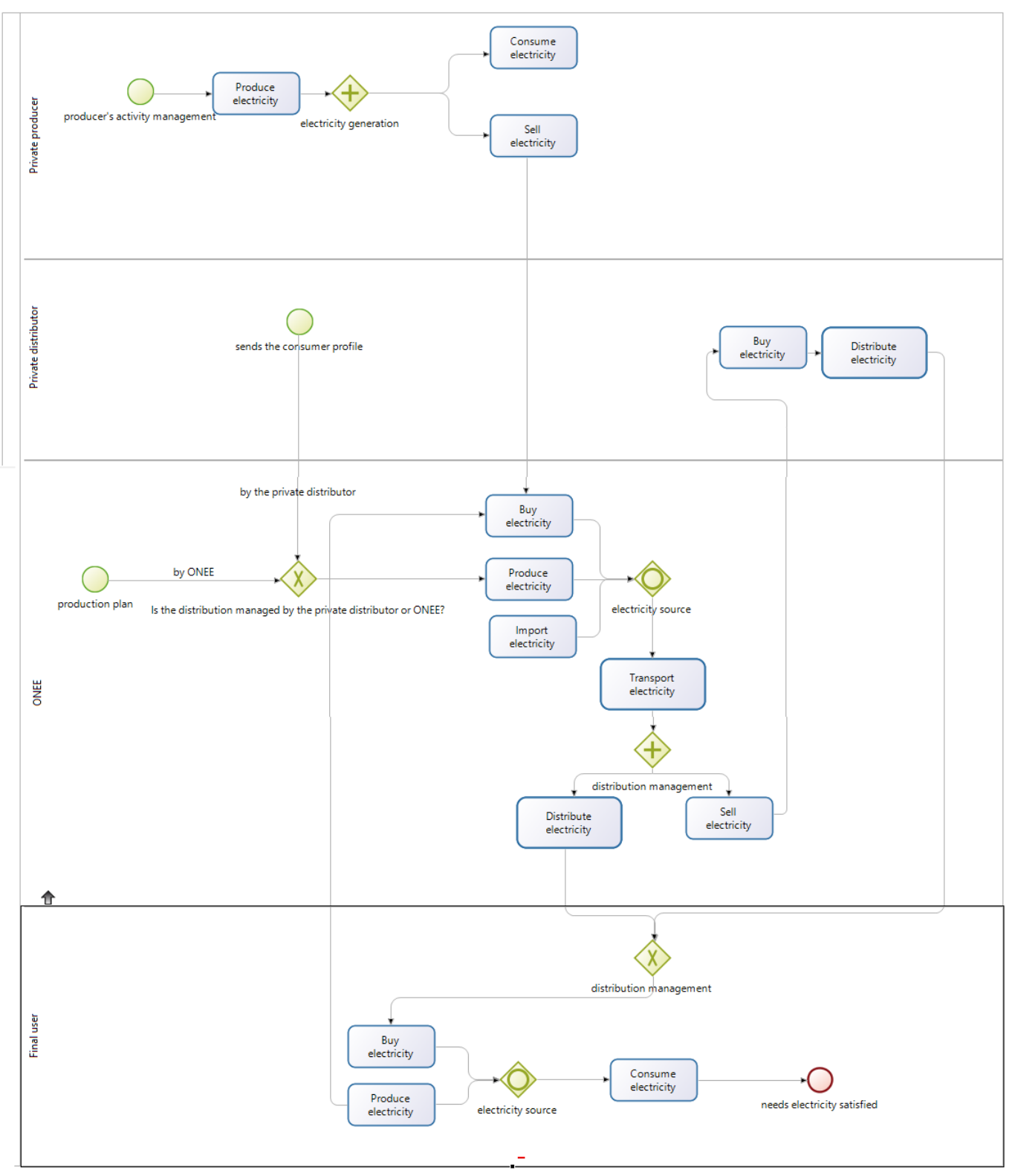

Figure 4. The proposed busines process 'management of electricity for residential buildings'

Once we clarified the way the characteristics of the Smart supply chain would improve the studied business process and emphasize the intelligence of our SSC, we go to RQ3, whose answer will clarify the way the changes made in the previous phase will be controlled.

RQ3: how can the reliability and reactivity of the proposed supply chain be evaluated?

\subsection{Control phase}

The last phase of Six Sigma's DMAIC model is the Control phase. The aim of this phase is to maintain the changes created in the previous phase. For this a dashboard composed of Steering and Performance indicator was elaborated. As a part of our goal to evaluate the continuity between the electricity production and its consumption, and obviously to evaluate how much the smart electrical supply chain is interconnected we are interested in the two attribute: 'Supply Chain Reliability' and 'Supply Chain Responsiveness' as defined in the first level of SCOR.

The chosen SCOR metric for 'Reliability' is 'Perfect Order Fulfillment'. The formula given by the model for it is : [Total Perfect Orders]/[Total Number of Orders]. Based on this indicator, and given the context of our case study, the indicator that corresponds functionally to the 'Perfect Order Fulfillment' is 'Rate of electricity supply': [electricity production expressed in Twh/an]/[electricity consumption: expressed in primary energy $\mathrm{kWhep} / \mathrm{m} 2 / y e a r$, the area is considered the living area].

Proposal for an approach to evaluate continuity in service supply chains: case of the ... (Houda Mezouar) 
'Responsiveness' is the speed at which tasks are performed. The chosen metric for this attribute is 'Order Fulfillment Cycle Time'. It represents the time passed between the moments a customer places the order to the moment the order is fulfilled. To calculate the 'Order Fulfillment Cycle Time' SCOR specifies: [Sum Actual Cycle Times for All Orders Delivered]/[Total Number of Orders Delivered]. Based on this indicator, and given the context of our case study, the indicator that corresponds functionally to the 'Order Fulfillment Cycle Time' is 'Rate of Electricity access'; [consumption duration - outages duration]/[consumption duration].

And based on $[16,19,20]$ which tackled the same supply chain in the three levels of SCOR with the same objectif of evaluation the continuity in this SSC, we regrouped the following performance indicators related to the attributes 'Accessibility' and 'Availability':

Accessibility:

- Population with access to power (\% of pop. in utility service area).

- Number of residential Subscribers per 100 Households in the Concession Area (Residential Coverage). Availability:

- Energy losses in Distribution per Year (\%).

- Average duration of interruptions per subscriber (Hours/year).

- Average frequency of fnterruptions per subscriber (Interruptions/year).

And to recapitulate the Table 4 presents the dashboard that sum up these indicators.

Table 4. Dashborad

\begin{tabular}{|c|c|c|c|}
\hline Attribute & Indicator & Indicator type & Calculation periodicity \\
\hline Reliability & $\begin{array}{l}\text { [electricity production expressed in } \\
\text { Twh/an]/[electricity consumption: expressed } \\
\text { in primary energy kWhep/m2 / year, the area } \\
\text { is considered the living area] }\end{array}$ & Steering indicator & A trimester \\
\hline Responsiveness & $\begin{array}{l}\text { [consumption duration - outages duration] / } \\
\text { [consumption duration] }\end{array}$ & Steering indicator & A trimester \\
\hline \multirow[t]{2}{*}{ Accessibility } & $\begin{array}{l}\text { Population with access to power ( } \% \text { of pop. } \\
\text { in utility service area) }\end{array}$ & Performance indicator & A year \\
\hline & $\begin{array}{l}\text { Number of residential Subscribers per } 100 \\
\text { Households in the Concession Area } \\
\text { (Residential Coverage) }\end{array}$ & Performance indicator & A year \\
\hline \multirow[t]{3}{*}{ Availability } & Energy losses in Distribution per Year (\%) & Performance indicator & A year \\
\hline & $\begin{array}{l}\text { Average duration of interruptions per } \\
\text { subscriber (Hours/year) }\end{array}$ & Performance indicator & A year \\
\hline & $\begin{array}{l}\text { Average frequency of fnterruptions per } \\
\text { subscriber (Interruptions/year) }\end{array}$ & Performance indicator & A year \\
\hline
\end{tabular}

To implement these indicators, several methodological steps are necessary:

- Define the scope to study to calibrate the type of data to be collected.

- Define energy-consuming activities to consider in identifying technology solutions to mobilize to collect data. of indicators.

Set the type of energy and the collection of scale (spatial, temporal ...) to calibrate the choice

\section{CONCLUSION}

This work presents a new approch to evaluate SCC performance. The proposed approach is based on DMAIC method of Six Segma, and combined BPM, SCOR, Smart supply chain, and Root cause analysis tree diagram. It's proven by the case study of evaluating the continuity in the Moroccan electricity SSC. By applying the aforementioned approach, the results and analysis gives us an overall overview of the studied SSC, establishes the causes behind the service discontinuity, proposed an improved version of the chosen business process, elaborates a dashboard to evaluate the chosen metric for this case (continuity). More case studies can be used to more thoroughly evaluate the presented approach, that can be improved by generalizing it to all SSC business processes. 


\section{REFERENCES}

[1] H. Mezouar and A. El Afia, "Performance analysis model for service supply chains: case of the retirement supply chain," International Journal of Engineering \& Technology, vol. 7, pp. 1429-1438, 2018.

[2] H. Mezouar and A. El Afia, "Proposal of a modeling approach and a set of KPI to the drug supply chain within the hospital," The 3rd IEEE International Conference on Logistics Operations Management (GOL), pp. 1-6, 2016.

[3] S. Erlinghagen, et al., "Smart meter communication standards in Europe - a comparison," Renewable and Sustainable Energy Reviews, vol. 43, pp. 1249-1262, 2015.

[4] K. Sharma and L. M. Saini, "Performance analysis of smart metering for smart grid: An overview," Renewable and Sustainable Energy Reviews, vol. 49, pp. 720-735, 2015.

[5] C. Zhanga, et al., "On electricity consumption and economic growth in China," Renewable and Sustainable Energy Reviews, vol. 76, pp. 353-368, 2017.

[6] G. Pepermans, "Valuing smart meters," Energy Economics, vol. 45, pp. 280-294, 2014.

[7] M. E. H. Dyson, et al., "Using smart meter data to estimate demand response potential, with application to solar energy integration," Energy Policy, vol. 73, pp. 607-619, 2014.

[8] F. E. H. Velasco, et al., "DC-AC power inverter controlled analogically with zero hysteresis," International Journal of Electrical and Computer Engineering (IJECE), vol. 9(6), 2019.

[9] H. Mezouar and A. El Afia, "A process simulation model for a proposed Moroccan supply chain of electricity," 2016 IEEE International Renewable and Sustainable Energy Conference (IRSEC), pp. 647-654, 2016.

[10] A. El Afia and H. Mezouar, "A global mapping of the Moroccan supply chain of hospital drugs, and a simulation of the dispensation process," International Conference on Big Data, Cloud and Applications (BDCA), vol. 108, 2017.

[11] H. Mezouar and A. El Afia, "A Retirement Pension from a Supply Chain Side: Case of the Moroccan Retirement Pension," Lecture Notes in Networks and Systems, Springer, vol. 25, pp. 103-115, 2017.

[12] H. Mezouar and A. El Afia, "Proposal of An Approach to Improve Business Processes of a Service Supply Chain," International Journal of Mechanical Engineering and Technology, vol. 10, pp.76-87, 2019.

[13] B. Ambore and Suresh L., "Novel model for boosting security strength and energy efficiency in internet-of-things using multi-staged game," International Journal of Electrical and Computer Engineering (IJECE), vol. 9(5), pp. 4326-4335, 2019.

[14] T. M. P. J. Pepper and T. A. Spedding, "The evolution of lean Six Sigma," International Journal of Quality \& Reliability Management, vol. 27, pp. 138-155, 2010

[15] J. Muraliraj, et al., "Annotated methodological review of Lean Six Sigma," International Journal of Lean Six Sigma, vol. 9, pp. 2-49, 2018.

[16] H. Mezouar, et al., "Toward a process model of Moroccan electric supply chain," International Conference on Electrical and Information Technologies (ICEIT), pp. 184-191, 2015.

[17] H. Mezouar, et al., "A new concept of intelligence in the electric power management," 2016 IEEE International Conference on Electrical and Information Technologies (ICEIT), pp. 28-35, 2016.

[18] K. Butner, "The smarter supply chain of the future," Strategy \& Leadership, vol. 38, pp. 22-31, 2010.

[19] K. G. Santo, et al., "A review on smart grids and experiences in Brazil," Renewable and Sustainable Energy Reviews, vol. 52, pp. 1072-1082, 2015.

[20] L. A. Lefebvre, et al., "RFID: An Emerging Paradigm for the Agrifood Supply Chain," Intelligent Agrifood Chains and Networks, vol. 1, pp. 109-129, 2011.

\section{BIOGRAPHIES OF AUTHORS}

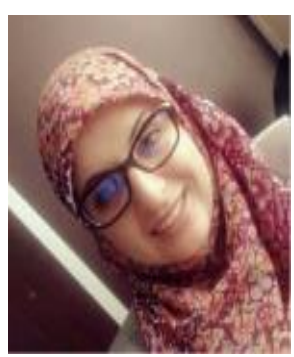

Houda Mezouar received her engineer degree in Computer science in 2011 at the National School of computer science and systems analysis (ENSIAS) School, Rabat, Morocco. In 2014, she joined the "Operational Research and Logistics" Research Laboratory of Mohamed V University in Rabat, Morocco. Her actual main research interests concern Smart Supply chain, Machine learning and Adaptive information systems.

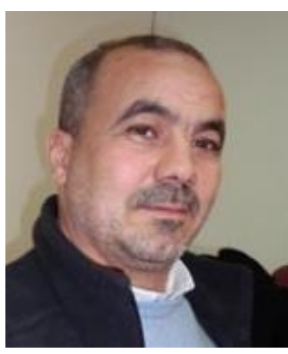

Abdellatif El Afia is an Associate Professor at National School of Computer Scienceand Systems Analysis (ENSIAS), Rabat, Morocco. He received his M.Sc. Degrees in Applied Mathematics from University of Sherbrook. He obtained his Ph.D. In 1999 in Operation Research from University of Sherbrook, Canada. Research areas of interest are Mathematical Programming (Stochastic and deterministic), Metaheuristics, Recommendation Systems and Machine Learning. 